\title{
Employees' Perceptions of Workplace Preparedness for Climate Change-Related Natural Hazards
}

\author{
Abdul-Akeem A. Sadiq, Meredith Ollier, Jenna Tyler
}

\section{Introduction}

In recent years, scholars and policymakers have expressed a mounting concern over the impacts of natural hazards related to the global threat of climate change (O'Brien, O'Keefe, Rose, \& Wisner, 2006). Such hazards, according to the Intergovernmental Panel on Climate Change (IPCC, 2012a), include, but are not limited to heat waves, droughts, floods, and wildfires. These climate change-related hazards (hereinafter referred to as cc hazards) have not only become more severe and frequent in recent decades, but are projected to continue to increase in severity, frequency, spatial extent, and duration in years to come (IPCC, 2012a, 2013). In light of this prediction, human systems, including societies, organizations, and individuals have been encouraged to adapt to future climatic changes to limit physical and economic losses (Adger, Arnell, \& Tompkins, 2005). Although adaptation, in the purview of climate change, broadly refers to adjustments made by human systems in response to the adverse impacts from climatic events (Adger, Arnell, \& Tompkins, 2005; IPCC, 2007), this study seeks to empirically examine the extent to which workplaces have adapted to cc hazards by describing employees' perceptions regarding their organizations' preparedness for cc hazards.

Preparedness involves actions undertaken by organizations in readiness for an emergency or disaster such as obtaining a first aid kit or extra medical supplies, providing employees with information on where to meet after disasters, and offering disaster preparedness and response training programs for employees (Sadiq \& Graham, 2015). Understanding the degree to which workplaces are prepared for cc hazards is important given that individuals and organizations have historically viewed the concept of climate change as nebulous and ambiguous (Berkhout, Hertin, \& Gann, 2006), and there is a lack of certainty about the type, severity, or time of onset of cc hazards (Winn et al., 2011). ${ }^{1}$ Consequently, organizations may not adequately prepare for the physical impacts of climate change albeit the direct effects of climate change can have lasting and devastating consequences. Such direct effects include, but are not limited to, physical damage to facilities, economic losses, higher operating costs, and disruptions in operations (Center for Climate and Energy Solutions (C2ES), 2013). However, when workplaces prepare for the adverse impacts of cc hazards, these direct effects can be minimized thus allowing workplaces to maintain their production and continue to contribute to the general and economic wellbeing of their community (Burns \& Slovic, 2012).

Considering the potential for significant losses and forecasts suggesting increases in the frequency and intensity of cc hazards (IPCC, 2012a, 2013), it is clear that there needs to be a better understanding of what workplaces have done to alter their exposure and vulnerability to cc hazards. To contribute to this limited research, we study employees' perceptions of their workplaces' preparedness levels and examine two research questions. (1) "Are workplaces prepared for cc hazards?" By exploring this question, we hope to acquire a broader understanding of workplace preparedness for cc hazards whereby the findings will serve as the groundwork for future studies. Then, we seek to understand if employees' perceptions of workplaces preparedness for cc hazards parallel with state preparedness priorities. Thus, our

\footnotetext{
${ }^{1}$ Because organizational preparedness is operationalized as perceived preparedness level at the facility where employees report to work, we use the terms organization and workplace interchangeably.
}

This is the author's manuscript of the article published in final edited form as:

Sadiq, A.-A. A., Ollier, M., \& Tyler, J. (2016). Employees' Perceptions of Workplace Preparedness for Climate Change-Related

Natural Hazards. Risk, Hazards \& Crisis in Public Policy, 7(2), 62-78. http://doi.org/10.1002/rhc3.12095 
second research question is: (2) "Does workplace preparedness for cc hazards align with state hazard priorities for cc hazards?" An inquiry to this question is important as it will reveal if workplaces are effectively utilizing their resources to prepare for the cc hazards that state emergency management agencies deem are most peculiar to their community. Together, this study ultimately seeks to bring familiarity to how organizations are effectively preparing for an otherwise "black box" concept - climate change. It is important to note that the goal of this preliminary study is not to test any hypotheses, but to describe what is going on within workplaces in terms of cc preparedness.

Using data collected from a national, online survey of 2,008 employees in the United States, the results suggest a need for workplaces to increase their level of preparedness for cc hazards. The results also highlight the importance of risk communication in helping workplaces better align their preparedness for cc hazards with their states' preparedness priorities for cc hazards. This preliminary study contributes to the literature on organizational preparedness for cc hazards by providing insights on the current state of workplace preparedness - from the perspectives of employees - for natural hazards associated with climate change. In the following section, we review the three cc hazards of interest-droughts/heatwaves, floods, and wildfires. Then, we discuss the extant literature on climate change adaptation and workplace preparedness. Next, we explain the method of data collection, variable measurement, and discuss the results. Finally, this paper concludes with a policy recommendation and provides an outline for future research on workplace preparedness for cc hazards.

\section{Literature Review}

\section{Climate Change-Related Natural Hazards}

In this study, we observe three cc hazards - droughts/heat waves, floods, and wildfires. This selection was made for two distinct reasons. First, these three natural hazards have the probability of occurring in all geographical regions in the United States. And second, the IPCC (2012a, 2012b) has recognized that these three natural hazards are associated with climate change (IPCC). This study conforms to the IPCC's (2012b, p. 557) definition of climate change as "the climate that can be identified (e.g., by using statistical tests) by changes in the mean and/or the variability of its properties, and that persists for an extended period, typically decades or longer". We also follow the lead of the IPCC by not distinguishing between anthropogenic and non-anthropogenic climate change (UNFCCC, 2011). This is because, irrespective of the causes of climate change, evidence suggests that the global temperature is increasing. For instance, the decade of 2001-2010 was the warmest decade since global records began in 1850 (IPCC, 2013; World Meteorological Organization (WMO), 2014). Likewise, 2015 was noted as the warmest year on record (National Oceanic and Atmospheric Administration (NOAA), 2015). In sum, our goal is not to engage in the debate on the systematic causes of climate change, but to recognize that certain natural hazards are associated with climate change, and these hazards have increased in frequency and severity in recent years.

\section{Drought/Heat Waves}

Droughts are prolonged periods of abnormally low rainfall, and heat waves are prolonged periods of unusually hot weather. Droughts and heatwaves are grouped together in this study because heat waves contribute to drought conditions by depleting soil moisture content and 
increasing evaporation, which results in increased surface heating and drying (Hansen, Sato, \& Ruedy, 2012). Based upon physical considerations, the intensity and frequency of heat waves and droughts are likely to increase due to higher mean temperatures (Coumou \& Rahmstorf, 2012; IPCC, 2013).

\section{Floods}

Flooding is the most destructive natural hazard in terms of fatalities, injuries, and economic losses (Jonkman, 2005; Sadiq \& Noonan, 2015). While this study did not distinguish between the different types of flooding, forecasts suggest that there will be increases in the frequency, intensity, and quantity of heavy precipitation events. Similarly, the warming of the oceans and thermal expansion, along with the melting of glacier ice, contribute to rising sea levels and it is likely that an increased incidence and/or magnitude of extreme high sea levels will have an impact on human systems, especially along the coast (IPCC, 2013)

\section{Wildfires}

Recent years have shown an influx in the frequency and magnitude of wildfire events. In fact, out of the 29 presidentially declared wildfire disasters, 22 have occurred since 2000 (Federal Emergency Management Agency (FEMA), 2016). While climate change is not the sole cause of wildfires, drier soil and vegetation resulting from increased temperatures make areas more prone to wildfires (C2ES, 2011). Heat waves over the United States contributed to the outbreak of wildfires in 2012 (UNISDR, 2013), and the combination of hot temperatures, strong winds, and drought conditions contributed to the worst wildfire in Colorado's history in 2013 (WMO, 2014). In the Unites States, the length of the fire season has increased by 78 days compared to nearly three decades ago (Westerling et al., 2006), and the frequency and size of wildfires has substantially risen (C2ES, 2011).

\section{Climate Change Adaptation}

The concept of climate change adaptation has been given increased attention over the past decade (Gerber, 2014). According to the IPCC (2007), adaptation refers to "adjustments in natural or human systems in response to actual or expected climatic stimuli or their effects..." Stemming from this definition, social scientists have used the concept of adaptation to understand human systems' perceptions and adjustments to natural hazards (Burton, Kates, \& White, 1978; Smit \& Wandel, 2006). Adaptation can then be viewed in a variety of different forms. For example, adaptation can be viewed as anticipatory or reactive whereby the former refers to human systems taking into account future trends and proactively employing measures to limit losses prior to the event (Environmental Protection Agency (EPA), 2012; Smit \& Wandel, 2006; Van Aalst, Cannon, \& Burton, 2008), and the latter focuses on making changes following a significant climatic event (Klein, 2003). Adaptation is also viewed as planned or autonomous (EPA, 2012). While planned adaptation refers to a deliberate policy decision that is based on conditions suggesting that action is required to limit any future losses, autonomous adaptation refers to human systems acting in their own self-interest to take actions in response to changing conditions regardless of any policy (Klein, 2003). Understanding the extent to which human systems have proactively and autonomously been successful in reducing the impacts of climate change is of great importance to both scholars and policymakers (Klein, 2003). 
According to Adger, Arnell, and Tompkins (2005), successful adaptation is contingent upon human systems' ability to reduce their sensitivity, alter their exposure, and increase their resiliency to climate change. Actions taken to reduce human systems' sensitivity to climate change include making changes to infrastructures through building codes and zoning. Altering a systems' exposure to climate change is achieved by investing in preparedness measures and developing disaster plans (Adger, Arnell, \& Tompkins, 2005; Smit \& Wandel, 2006). Finally, adaptation actions are intended to promote the resilience of human systems despite a changing climate (Gerber, 2014). Resilience, according to Tierney (2013), refers to a system's ability to resist, absorb, and bounce back from adverse natural hazard events. Ultimately, adaptation activities are designed to enhance the ability of human systems to adjust and adapt to the negative impacts engendered by climate change-related natural disasters.

\section{Organizational Preparedness}

While the ongoing discussion has focused on human systems in general, we now turn to organizations in particular as the goal of the present study is to understand the extent to which workplaces are prepared for cc hazards through the perceptions of their employees. Organizations are critical entities in any society; they provide goods and services to community members and contribute to the economic and general wellbeing of the community they serve (Sadiq \& Graham, 2015). Yet, when confronted by cc hazards, organizations can suffer considerable damage to facilities, economic losses, higher operating costs, and disruptions in operations (IPCC, 2012b; Schulte \& Chun, 2009; Winn et al., 2011). To minimize these negative effects, organizations are encouraged to invest in preparedness measures. However, the decision to act can be difficult as there is uncertainty about the type, severity, or time of onset of cc hazards (Winn et al., 2011). Consequently, organizations may perceive climate change and its impacts as ambiguous, far-reaching, and unpredictable (Berkhout, Hertin, \& Gann, 2006; Winn et al., 2011). This is evidenced by Brody et al. (2010) study of 1,528 agency personnel from local and regional public sector organizations. Specifically, this study sought to understand the extent to which public sector organizations incorporated climate change-related mitigation and adaptation strategies in their planning and policymaking activities. The results showed that in general, public sector organizations do not view climate change as an immediate threat requiring action. Similar arguments have been made by Lorenzoni et al. (2006) and Sterman and Sweeney (2007) who both suggest that the public does not view climate change as an immediate and high priority threat. However, there is scientific evidence suggesting that cc hazards have become more severe and frequent in recent decades, and as a result, it is imperative for organizations to adapt to future climatic changes by investing in preparedness (Adger, Arnell, \& Tompkins, 2005; Berkhout, Herlin, \& Gann, 2006; IPCC, 2013).

\section{Data and Methodology}

\section{Data Collection}

One of the authors was part of the research team that developed the survey instrument and administered it through GfK. GfK is one of the largest global survey research organizations and has approval from the National Institute of Health to conduct survey research. The instrument collected the following information, among others, from respondents: their perceptions of their 
employers' level of preparedness for different natural hazards; employee demographics; and characteristics of employees' organization. A pre-test of the survey instrument was conducted with a test group consisting of 17 staff and alumni of a university in Midwestern United States from December 12 to December 20, 2013. The minor issues that were revealed during the pretest were corrected.

After making these corrections, the survey was shared with GfK for an initial pilot of 100 individuals in their KnowledgePanel ${ }^{\circledR}$ (more information on GfK's KnowledgePanel ${ }^{\circledR}$ is available at http://join.knpanel.com/about.html). The KnowledgePanel ${ }^{\circledR}$ is based on a representative random sample of the United States population. Members of the KnowledgePanel ${ }^{\circledR}$ are recruited using random-digit dialing and address-based sampling methods that include both households with and without Internet access. If the sampling selects households that have neither an Internet connection nor a computer, GfK provides both to them at no charge. As a result, the KnowledgePanel ${ }^{\circledR}$ provides a nearly complete coverage of the United States population. Compared to random digit dialing and non-probability Internet surveys, probabilitybased Internet panels yield more accurate results (Chang \& Krosnick, 2009). In addition, the American Association for Public Opinion Research (AAPOR) issued a report on online panels that stated studies using nonprobability sampling methods are generally less accurate than studies using probability sampling methods in cases where it is possible to compare survey results to external benchmarks like the Census (Baker et al., 2010). Conversely, Yeager and colleagues (2010) argue that there is no significant difference between non-probability and probability samples with regard to accuracy but conclude that probability samples provide a more accurate measurement of the distribution of variables within a population.

GfK fielded the online survey in May 2014 to a national sample of 10,559 United States adults, 18 years of age or older from their KnowledgePanel®. GfK sent one reminder to encourage participation. Of the 10,559 sample members invited to participate, 5,079 responded, and were then screened based on two eligibility criteria: 1) currently working as a paid employee for an employer other than themselves, and 2) not currently telecommuting for the majority of their work time. The authors are interested in measuring employees' perceptions of their employers' preparedness and not the perceptions of owners of workplaces. Also, the authors surveyed respondents that do not telecommute for the majority of their work time because the authors wanted respondents that are aware of the preparedness measures present at the facility where they report to work.

A total of 2,026 respondents passed the eligibility screening and completed the survey (the screening procedure eliminated 2,702 because they were not currently working and 351 because of telecommuting). After about four weeks, the survey was completed, and the data were given to the research team. The response rate for this survey is 48 percent, using the guidelines established by the AAPOR (www.aapor.org/Standard Definitions2.htm\#.U9fLRvldU1c). AAPOR's Response Rate 3 (RR3) was used, and calculated by dividing the 2,008 interviews by the sum of 2,026 known eligible cases plus 2,192 estimated eligible cases among the 5,480 who did not respond to the survey invitations (assuming an estimated eligibility rate of $40 \%$, based on the eligibility rate of the 5,079 respondents). GfK weighted the data to account for unequal probabilities of selection as well as to ensure that the data are as close as possible to Current Population Survey (CPS) estimates for the United States population vis-à-vis demographic characteristics (see Table 1).

The final sample size is 2,008 respondents after 18 ( 0.8 percent) cases were removed due to short completion times of less than five minutes. A common technique in survey research is to 
use completion time to identify respondents who may have sped through the survey without carefully reading or answering questions (Olson \& Parkhurst, 2013). A review of the 18 cases showed that respondents either failed to answer items after the initial demographic section, or exhibited 'straight-lining' (answering several sequential items with the same response).

Although the current research design was built upon two smaller studies, the data collected in the present survey is distinct in two respects. First, to the best of the authors' knowledge, the data used in this study is the largest survey to date measuring workplace preparedness for cc hazards. Second, this is one of a few known surveys that gathered information anonymously from a national sample of employees about their employer's level of preparedness. Surveying employees instead of the leaders of organizations is somewhat novel and may allow us to avoid two problems. First, sampling organizational leaders is likely to result in low response rates. For example, the response rate for surveying organizational leaders in Sadiq and Weible's (2010) and Han and Nigg's (2011) studies were 31 percent $(\mathrm{N}=227)$ and 33.6 percent $(\mathrm{N}=933)$, respectively. Second, there is a potential for biased responses from the leaders of organizations as leaders have an incentive to overstate their organizations' preparedness levels (Fowler, Kling, \& Larson, 2007; Larson \& Fowler, 2009). A variant of response bias is selection bias, whereby leaders of organizations that have adopted some preparedness measures may be more likely to respond to the survey than leaders of organizations that have not adopted any preparedness measure. By sampling employees, the authors hope to mitigate these two problems and get a more accurate picture of the level of organizational preparedness for cc hazards.

\section{Variable Measurement and Data Analysis}

The data analysis component comprised of two separate levels of analyses - national and state. The national-level analyses used all the observations in the sample, while the state-level analyses were restricted to state subsamples. The national-level analyses give a broad perspective, whereas the state-level analyses provide a more nuanced understanding of the regional differences in workplace preparedness for cc hazards.

The national level data are used to answer the first research question: "Are workplaces prepared for cc hazards?" As a result, the variable of interest, employee perceptions of workplace preparedness was measured by the following question on the survey: "On a scale of 1 (not prepared at all) to 5 (very prepared), please rate your perception of your employer's level of preparedness for [drought/extreme heat, flooding, and wildfires] at the facility where you report to work." A new variable was created, average preparedness for cc hazards by adding responses to the three cc hazards together and dividing the total by three. Information about which state an employee reports to work was measured by the question: "In which state do you report to work?"

The state subsample data and secondary data from state hazard mitigation plans are used to answer the second question: "Does workplace preparedness for cc hazards align with state hazard priorities for cc hazards?" To answer this question, we identified four states, each representing one of the four census regions in the United States - California, West; New York, East; Ohio, Midwest; and Texas, South. These four states were selected because each had the highest number of observations within their respective regions in the sample. After the selection, the authors visited the respective state emergency agencies' websites and obtained the latest copy of the states' hazard mitigation plan. Each hazard mitigation plan contained a ranking of hazards from most likely to least likely to occur within their state's jurisdiction. These rankings guide state hazard preparedness priorities. Specifically, rankings were based on: probability and 
stress/impact (State of California); HAZNY risk analysis methodology (State of New York); total risk (State of Ohio); predetermined rankings (State of Texas). Other natural hazards were rated in each state hazard mitigation plan. However, because our three hazards of interest are droughts/extreme heat, floods, and wildfires, we ranked these three hazards in consecutive order. For example, if a state hazard mitigation plan ranks four hazards in the following order: flood (1), earthquake (2), drought/heat (3), and wildfire (4), we eliminated earthquake and re-ranked the three remaining hazards in the following order: flood (1), drought/heat (2), and wildfires (3).

\section{Results}

Table 1 compares respondents' demographics for the weighted and unweighted samples to the CPS. The CPS data reported in Table 1 is for adult civilian workers that are 18 years and older. It is important to note that the CPS has no data on household heads (the CPS collected data on "householder", which is a slightly different concept) or one-family house detached. Lastly, the CPS has information on income over $\$ 100,000 .{ }^{2}$ According to Table 1 , the average age of the respondents in the sample was about 42 years old, nearly 70 percent were white, and 22 percent hold a Bachelor's degree. With regard to gender, 53 percent were male, and 80 percent were household heads, and the average household size was about three people. Further, 67 percent live in a one-family house, 14 percent make between $\$ 100,000$ and $\$ 124,999$ in income, and 52 percent are married. Finally, 85 percent reside in a metro area, 72 percent own their living quarters, and 86 percent have Internet access.

Table 1. Descriptive Statistics for the Full Sample (N=2008)

\begin{tabular}{|l|c|c|c|c|c|c|}
\hline & \multicolumn{1}{|c|}{$\begin{array}{c}\text { Weighted } \\
\text { Sample } \\
\text { Mean }\end{array}$} & Std. Dev. & Min. & Max. & $\begin{array}{c}\text { Unweighted } \\
\text { Sample Mean }\end{array}$ & $\begin{array}{c}\text { CPS 2013 } \\
\text { Estimates }\end{array}$ \\
\hline Variable Description & 41.81 & 13.853 & 18 & 86 & 44.87 & 42.49 \\
\hline Age & 0.69 & 0.463 & 0 & 1 & 0.73 & 0.66 \\
\hline White, Non-Hispanic & 0.22 & 0.418 & 0 & 1 & 0.26 & 0.22 \\
\hline Bachelor's degree & 0.53 & 0.499 & 0 & 1 & 0.55 & 0.53 \\
\hline Male & 0.80 & 0.397 & 0 & 1 & 0.83 & N/A \\
\hline Household Head & 2.73 & 1.404 & 1 & 10 & 2.72 & 2.81 \\
\hline Household Size & & & & & & \\
\hline $\begin{array}{l}\text { A one-family house } \\
\text { detached }\end{array}$ & 0.67 & 0.469 & 0 & 1 & 0.71 & N/A \\
\hline
\end{tabular}

\footnotetext{
${ }^{2}$ The demographic information is intended to give an idea of respondents who answered the survey, and will not be used for any statistical analyses in the current paper.
} 


\begin{tabular}{|l|c|c|c|c|c|c|}
\hline $\begin{array}{l}\text { Household Income } \\
(\$ 100,000 \text { to \$124,999) }\end{array}$ & 0.14 & 0.352 & 0 & 1 & 0.15 & \\
\hline Married & 0.52 & 0.500 & 0 & 1 & 0.56 & 0.55 \\
\hline MSA Status: Metro & 0.85 & 0.356 & 0 & 1 & 0.86 & 0.85 \\
\hline $\begin{array}{l}\text { Living Quarters owned } \\
\text { or being bought by } \\
\text { someone in household }\end{array}$ & 0.72 & 0.450 & 0 & 1 & & \\
\hline \begin{tabular}{l} 
HH Internet Access \\
\hline
\end{tabular} & 0.86 & 0.345 & 0 & 1 & 0.75 & 0.68 \\
\hline
\end{tabular}

Table 2, which presents information on the location of respondents comprising the subsample, indicates that about ten percent of respondents are from California. Respondents from New York, Ohio, and Texas represent about seven percent, four percent, and six percent, respectively. Descriptive statistics for national preparedness levels, presented in Table 3, show that the cc hazard with the highest mean preparedness level is drought/extreme heat (3.32), followed by flooding (2.99), then wildfire (2.50). The overall average for all cc hazards is 2.93.

\section{Table 2. State Subsample Statistics}

\begin{tabular}{|l|c|c|c|c|c|}
\hline State, region of the US & N & Mean & Std. Dev. & Min. & Max. \\
\hline California, West region & 198 & 0.099 & 0.298 & 0 & 1 \\
\hline New York, Northeast region & 136 & 0.068 & 0.251 & 0 & 1 \\
\hline Ohio, Midwest region & 82 & 0.041 & 0.198 & 0 & 1 \\
\hline Texas, South region & 122 & 0.061 & 0.239 & 0 & 1 \\
\hline
\end{tabular}

Table 3. Mean Perceived Level of Preparedness for CC Hazards for the Full Sample

\begin{tabular}{|l|c|c|c|c|c|c|c|}
\hline & N & Mean & $\begin{array}{c}\text { Std. } \\
\text { Dev. }\end{array}$ & Min. & Max. & \multicolumn{2}{|c|}{$\begin{array}{c}\text { 95\% Conf. } \\
\text { Interval }\end{array}$} \\
\hline CC Hazards & & & & & & & \\
\hline Drought/Extreme Heat & 1682 & 3.32 & 1.33 & 1 & 5 & 3.25 & 3.40 \\
\hline Flooding & 1650 & 2.99 & 1.33 & 1 & 5 & 2.91 & 3.07 \\
\hline Wildfires & 1406 & 2.50 & 1.41 & 1 & 5 & 2.41 & 2.59 \\
\hline Average & 1579 & 2.93 & 1.36 & 1 & 5 & 2.86 & 3.02 \\
\hline
\end{tabular}

Table 4 shows the mean preparedness for cc hazards for the four states. In California, the highest mean preparedness is for drought/extreme heat (3.37) followed by wildfires (3.03), and lastly flooding (2.77). In New York, the natural hazard with the highest mean preparedness is flooding (3.03), followed by drought/extreme heat (3.01) and wildfires (2.16). Drought/extreme heat has the highest mean preparedness in Ohio (3.23). The second and third positions are occupied by flooding (2.81) and wildfires (2.08), respectively. Finally, in Texas, drought/extreme heat (3.61) has the highest mean preparedness followed by flooding (2.99), and 
wildfires (2.72). In addition, Texas has the highest average mean preparedness for cc hazards (3.11) followed by California (3.06), New York (2.73), and Ohio (2.71).

Table 4. Mean Preparedness for cc Hazards for all Four States

\begin{tabular}{|l|c|c|c|c|}
\hline & \multicolumn{4}{|c|}{ Mean Preparedness } \\
\hline & California & New York & Ohio & Texas \\
\hline CC Hazards & & & & 3.61 \\
\hline Drought/Extreme Heat & 3.37 & 3.01 & 3.23 & 2.99 \\
\hline Flooding & 2.77 & 3.03 & 2.81 & 2.72 \\
\hline Wildfires & 3.03 & 2.16 & 2.08 & 3.11 \\
\hline Average & 3.06 & 2.73 & 2.71 & \\
\hline
\end{tabular}

One possible explanation for the moderate - and in some cases, less than moderatelevels of workplace preparedness for all cc hazards observed in the four states may be due to the varying levels of priority given to these natural hazards by each state. To investigate this possibility, the authors examined the hazard mitigation plans of the four states to see which of these three cc hazards were identified as primary concerns for the states. The authors then ranked the identified cc hazards based on their estimated risk values by the four states. Table 5 presents information about how the cc hazards were ranked by the four states' hazard mitigation plans. It is important to note that all the states identified the three cc hazards as priorities.

Table 5. Natural Hazard Ranking by State Hazard Mitigation Plans

\begin{tabular}{|l|l|l|l|l|}
\hline \multirow{2}{*}{ Rank } & \multicolumn{4}{|c|}{ CC Hazards } \\
\cline { 2 - 5 } & \multicolumn{1}{|c|}{ California } & \multicolumn{1}{c|}{ New York } & \multicolumn{1}{c|}{ Ohio } & \multicolumn{1}{c|}{ Texas } \\
\hline 1 & $\begin{array}{l}\text { Drought/Extreme } \\
\text { Heat (both were } \\
\text { ranked 1 and 2, } \\
\text { respectively) }\end{array}$ & $\begin{array}{l}\text { Flooding-coastal, } \\
\text { inland, ice-jams }\end{array}$ & $\begin{array}{l}\text { Flood-areal and } \\
\text { riverine, flash flood, } \\
\text { and seiche }\end{array}$ & Flood \\
\hline 2 & Wildfires & Drought & Drought & Wildfires \\
\hline 3 & Flooding & Wildfire & $\begin{array}{l}\text { Fire-forest, range, } \\
\text { urban, and wildland }\end{array}$ & Drought \\
\hline Source & $\begin{array}{l}\text { California } \\
\text { Governor's office of } \\
\text { Emergency Service } \\
(2014)\end{array}$ & $\begin{array}{l}\text { New York State } \\
\text { Division of } \\
\text { Homeland Security } \\
\text { and Emergency } \\
\text { Management (2014) }\end{array}$ & $\begin{array}{l}\text { Ohio Emergency } \\
\text { Management Agency } \\
\text { (2014) }\end{array}$ & $\begin{array}{l}\text { Texas Division of } \\
\text { Emergency } \\
\text { Management (2013) }\end{array}$ \\
\hline
\end{tabular}

Table 6 presents a comparison of the state cc hazard rankings and the mean preparedness rankings (based on mean preparedness values) by employees. State hazard rankings are in the left columns under state EM plan headings, while employee rankings are in right columns under survey headings. Two observations are worth mentioning. First, the State of California and the State of New York are the only states where priorities for cc hazards align perfectly with workplace preparedness rankings. Second, the state hazard rankings matched the mean 
preparedness rankings in 6 out of 12 total cases. In sum, state priorities for cc hazards align with workplace preparedness rankings in just half of the cases.

Table 6. Comparison of State Hazard Rankings with Employee Preparedness Rankings for cc Hazards

\begin{tabular}{|l|c|c|c|c|c|c|c|c|}
\hline & \multicolumn{9}{|c|}{ Rankings } \\
\hline & \multicolumn{2}{|c|}{ California } & \multicolumn{2}{c|}{ New York } & \multicolumn{2}{c|}{ Ohio } & \multicolumn{2}{c|}{ Texas } \\
\hline CC Hazards & $\begin{array}{c}\text { State } \\
\text { EM } \\
\text { Plan }\end{array}$ & Employee & $\begin{array}{c}\text { State } \\
\text { EM } \\
\text { Plan }\end{array}$ & Employee & $\begin{array}{c}\text { State } \\
\text { EM } \\
\text { Plan }\end{array}$ & Employee & $\begin{array}{c}\text { State } \\
\text { EM } \\
\text { Plan }\end{array}$ & Employee \\
\hline $\begin{array}{l}\text { Drought/ } \\
\text { Extreme Heat }\end{array}$ & 1 & 1 & 2 & 2 & 3 & 1 & 3 & 1 \\
\hline Flooding & 3 & 3 & 1 & 1 & 1 & 2 & 1 & 2 \\
\hline Wildfires & 2 & 2 & 3 & 3 & 2 & 3 & 2 & 3 \\
\hline
\end{tabular}

\section{Discussion}

At the national level, the results indicate that employees perceive their workplaces to be moderately prepared for cc hazards. The national-level results are corroborated by the results of the sub-analyses from the States of California, New York, Ohio, and Texas. In general, employees in all four states have moderate — and in some cases, less than moderate-workplace preparedness perception levels for the three cc hazards despite these cc hazards been identified as major environmental threats within their respective state hazard mitigation plans. The national and state level results support previous research that maintained that the public does not view climate change as an immediate and a high priority threat (Brody et al., 2010; Lorenzoni et al., 2006; Sterman \& Sweeney, 2007), as well as descriptions of climate change by researchers as a distant threat (Lorenzoni et al., 2006), a threat with a long response delay (Sterman \& Sweeney, 2007), an uncertain environmental threat (O'Connor, Bord, \& Fisher, 1999), and a predictable surprise (Bazerman, 2006).

The findings of this study also have practical implications for risk communication as the results indicated that organizations in the states of Ohio and Texas (and perhaps other states not considered in this study) are not preparing for the hazards that their respective state emergency management agencies have prioritized for their states. In fact, employees in both Ohio and Texas revealed that their workplaces are more prepared for droughts/heat waves than floods albeit flooding has a higher risk level than droughts/heat according to their respective state emergency management agencies. As a result, it is possible that organizations may not be getting the necessary preparedness information from their state emergency management agencies about cc hazards. It may also be the case that their state emergency management agencies may not be as effective in their means of sharing hazard related information compared to California and New York. Interestingly, employees in California, Ohio, and Texas reported that their organizations are most prepared for droughts/heat waves. This could potentially be attributed to the fact that organizations might view preparing for a drought/heat wave to be more affordable than preparing for a flood or wildfire. In fact, studies have found that individuals typically invest in less complicated and less expensive preparedness measures (Webb et al., 2000). 
The divergence between the state hazard mitigation plans and employees' survey responses is evidence that organizational preparedness for climate change is complex. It requires organizations to understand and assess the risk of multiple natural hazards against the backdrop of uncertainty (Birkmann, 2011). Projections from cc hazard assessments and impact scenarios, like the IPCC assessment reports, help inform organizations of anticipated impacts. However, these hypothetical assessments present a challenge for organizations because they are ambiguous and indirectly related to organizations (Berkhout, Hertin, \& Gann, 2006). To make matters worse, there are limitations on organizational preparedness including financial, technical, (Sadiq \& Weible, 2010), cognitive, structural, and political constraints (Bazerman, 2006). Furthermore, the contradiction of beliefs and opinions of the public and the schisms between the public and the scientific community about climate change may hinder the adoption of preparedness measures for cc hazards. However, awareness of the physical impacts of climate change on organizations can ameliorate this issue. Just as public opinion influences government policies (Sterman \& Sweeney, 2007), it can create a solid foundation for implementing organizational preparedness policies for cc hazards (Yu et al., 2013).

With climate change impacts on organizations expected to increase, organizations need to increase their level of preparedness for cc hazards, especially those examined in this study, and have been identified as major priorities by the four states' emergency management offices. In order for organizations to invest in preparedness, they need to first understand the risks and associated impacts of cc hazards. In fact, organizational awareness of the physical risks and potential impacts is the first step in managing risk from cc hazards (C2ES, 2013). Thus, an understanding of perceived organizational preparedness for cc hazards is also necessary for future recommendations regarding organizational investment in preparedness measures for cc hazards.

The following two limitations provide opportunities for researchers to improve this study. First, employees may not be aware of the preparedness measures implemented by their workplaces. Nonetheless, by asking employees about the level of preparedness at the facility they report to work, and by making sure that employees are present at those facilities for a majority of their work time, the authors may have been unable to reduce the potential bias stemming from ignorance. Second, this study used perceived organizational preparedness, not actual preparedness measures adopted by organizations, as measures of preparedness. Although the latter may result in more accurate measures of organizational preparedness than the former, the use of perceptual measures is prevalent among scholars (e.g., Brody et al., 2008; Fowler, Kling, \& Larson, 2007; Poussin et al., 2014; Chikoto, Sadiq, \& Fordyce, 2013; Sadiq, 2011; Sadiq \& Weible, 2010). Despite raising more questions than answers, this study provides the basis for future organizational preparedness research on climate change-related natural hazards. For example, future studies might inquire into the reasons for the low levels of workplace preparedness and why state natural hazard rankings are not better aligned with workplace preparedness rankings for the states of Ohio and Texas. Finally, future studies should replicate our study using all the 50 states. In so doing, researchers, policymakers, and practitioners will have a more comprehensive understanding of workplace preparedness, and a better understanding of the relationship between workplace preparedness rankings and state cc hazard priorities.

\section{Conclusions}


This preliminary study contributes to the literature on organizational preparedness for cc hazards in two ways. First, the current study describes the current state of workplace preparedness - from the perspectives of employees - for natural hazards associated with the global threat known as climate change. Second, this study illuminates the connection between natural hazards and climate change. Organizations must be aware of the physical impacts of climate change in order to adapt. However, studies have shown that the concept of climate change is nebulous and ambiguous for individuals and organizations (Berkhout, Hertin, \& Gann, 2006). Studying natural hazards related to climate change might bring familiarity to an otherwise "black box" conceptclimate change. Consequently, the findings regarding workplace preparedness for climate change-related natural hazards may offer insights into how organizations are preparing for climate change. In sum, if the IPCC reports (IPCC, 2012a; IPCC, 2012b) are anything to go by, the low workplace preparedness levels as well as the mismatch between two state natural hazard preparedness priorities and mean preparedness rankings suggest that more needs to be done to prepare workplaces for the impacts of climate change.

The mismatches between state preparedness priorities for cc hazards and employees' preparedness rankings for the States of Ohio and Texas, present an opportunity for a policy recommendation. The state governments of Ohio and Texas (and perhaps, other states that may be experiencing the same problem) should implement risk communication programs aimed at disseminating information about natural hazard priorities to organizations. A risk communication program might consist of community awareness campaigns regarding the cc hazards most peculiar to a particular community and the preparedness measures needed by organizations to reduce the impacts from those hazards. In doing so, state governments can improve the alignment between their state's preparedness priorities and organizational preparedness for climate change-related natural hazards, thus enhancing organizational resilience to climate change.

Although, this preliminary study is descriptive in nature, it helps to lay the foundation for future research. Moreover, our study represents the first piece of the puzzle in assessing organizational preparedness for cc hazards. More research is needed on other puzzle pieces such as the future research topics discussed above. Once all these puzzle pieces are put together, organizational decision-makers, policymakers, and the public will have a better and more comprehensive understanding of organizational preparedness for climate change-related natural hazards. 


\section{References}

Adger, Neil W., Nigel W. Arnell, and Emma L. Tompkins. 2005. "Successful Adaptation to Climate Change Across Scales." Global Environmental Change 15 (2): 77-86.

Baker, Reg, Stephen J. Blumberg, J. Michael Brick, Mick P. Couper, Melanie Courtright, J. Michael Dennis, Don Dillman et al. 2010. "Research Synthesis AAPOR Report on Online Panels." Public Opinion Quarterly 74 (4): 711-781.

Bazerman, Max H. 2006. "Climate Change as a Predictable Surprise." Climatic Change 77 (1): 179-193.

Berkhout, Frans, Julia Hertin, and David M. Gann. 2006. "Learning to Adapt: Organisational Adaptation to Climate Change Impacts." Climatic Change 78 (1): 135-156.

Birkmann, Jörn. 2011. "First-and Second-Order Adaptation to Natural Hazards and Extreme Events in the Context of Climate Change." Natural Hazards 58 (2): 811-840.

Brody, Samuel D., Himanshu Grover, Eric Lindquist, and Arnold Vedlitz. 2010. "Examining Climate Change Mitigation and Adaptation Behaviours among Public Sector Organisations in the USA." Local Environment 15 (6): 591-603.

Brody, Samuel D., Sammy Zahran, Arnold Vedlitz, and Himanshu Grover. 2008. "Examining the Relationship Between Physical Vulnerability and Public Perceptions of Global Climate Change in the United States." Environment and Behavior 40 (1): 72-95.

Burns, William J., and Paul Slovic. 2012. "Risk Perception and Behaviors: Anticipating and Responding to Crises." Risk Analysis 32 (4): 579-582.

Burton, Ian, Bob Kates, and Gilbert White. 1978. The Environment as Hazard. New York: Oxford University Press.

California Governor's Office of Emergency Service. 2014. "California Threat and Hazard Survey: Data Sets and Charts." http://www.caloes.ca.gov/PlanningPreparednessSite/Documents/06\%20Hazard $\% 20$ and $\%$ 20Threats $\% 20$ Data $\% 20$ Set $\% 20$ and $\% 20$ Charts $\% 20$ with $\% 20$ Cover.pdf

Center for Climate and Energy Solutions (C2ES). 2011. "A Climate of Extreme Weather Events." http://www.c2es.org/docUploads/Climate-Extreme-Weather.pdf

Center for Climate and Energy Solutions (C2ES). 2013. "Weathering the Storm: Building Business Resilience to Climate Change." http://www.c2es.org/publications/weatheringstorm-building-business-resilience-climate-change

Chang, Linchiat, and Jon A. Krosnick. 2009. "National Surveys via RDD Telephone Interviewing Versus the Internet: Comparing Sample Representativeness and Response Quality." Public Opinion Quarterly 73 (4): 641-678.

Chikoto, Grace L., Abdul-Akeem Sadiq, and Erin Fordyce. 2013. "Disaster Mitigation and Preparedness Comparison of Nonprofit, Public, and Private Organizations." Nonprofit and Voluntary Sector Quarterly 42 (2): 391-410.

Coumou, Dim, and Stefan Rahmstorf. 2012. "A Decade of Weather Extremes." Nature Climate Change 2 (7): 491-496.

Environmental Protection Agency (EPA). 2012. "State and Local Climate and Energy Program." http://www.epa.gov/statelocalclimate/index.html

Federal Emergency Management Agency. 2016. "Disaster Declarations." https://www.fema.gov/disasters

Fowler, Karen L., Nathan D. Kling, and Milan D. Larson. 2007. "Organizational Preparedness for Coping with a Major Crisis or Disaster.” Business and Society 46 (1): 88-103. 
Gerber, Brian J. 2014. "Climate Change as a Policy Development and Public Management Challenge: An Introduction to Key Themes." Risk, Hazards \& Crisis in Public Policy 5 (2): 97-108.

Han, Ziqiang, and Joanne Nigg. (2011). “The Influences of Business and Decision Makers' Characteristics on Disaster Preparedness-A study on the 1989 Loma Prieta Earthquake." International Journal of Disaster Risk Science 2 (4): 22-31.

Hansen, James, Makiko Sato, and Reto Ruedy. 2012. "Perception of Climate Change." Proceedings of the National Academy of Sciences 109 (37): E2415-E2423.

Intergovernmental Panel on Climate Change (IPCC). 2007. "Climate Change 2007:Working Group III: Mitigation of Climate Change-Glossary E-I." www.ipcc.ch/publications and data/ar4/wg3/en/annex1-ensglossary-e-i.html

Intergovernmental Panel on Climate Change (IPCC). 2012a. "Summary for Policymakers." In Managing the Risks of Extreme Events and Disasters to Advance Climate Change Adaptation." A Special Report of Working Groups I and II of the Intergovernmental Panel on Climate Change, eds. Christian B. Field, Vincente Barros, Thomas F. Stocker, Qin Dahe, David J. Dokken, Kristie L. Ebi, Michael D. Mastrandrea, Katharine J. Mach, Gian-Kasper Plattner, Simon K. Allen, Melinda Tignor, and Pauline M. Midgley. Cambridge, UK, and New York, NY, USA: Cambridge University Press, 1-19.

Intergovernmental Panel on Climate Change (IPCC). 2012b. "Glossary of Terms." In Managing the Risks of Extreme Events and Disasters to Advance Climate Change Adaptation." A Special Report of Working Groups I and II of the Intergovernmental Panel on Climate Change, eds. Christian B. Field, Vincente Barros, Thomas F. Stocker, Qin Dahe, Kristie L. Ebi, Michael D. Mastrandrea, Katharine J. Mach, Gian-Kasper Plattner, Simon K. Allen, Melinda Tignor, and Pauline M. Midgley. Cambridge, UK, and New York, NY, USA: Cambridge University Press, 555-564.

Intergovernmental Panel on Climate Change (IPCC). 2013. "Summary for Policymakers." In Climate Change 2013: The Physical Science Basis." Contribution of Working Group I to the Fifth Assessment Report of the Intergovernmental Panel on Climate Change, eds. Thomas F. Stocker, Qin Dahe, Gian-Kasper Plattner, Melinda Tignor, Simon K. Allen, Judith Boschung, Alexander Nauels, Yu Xia, Vincent Bex, and Pauline M. Midgley. Cambridge, United Kingdom and New York, NY, USA Cambridge: University Press.

Jonkman, Sebastiaan N. 2005. "Global Perspectives on Loss of Human Life Caused by Floods." Natural Hazards 34 (2): 151-175.

Klein, Richard J. 2003. "Adaptation to Climate Variability and Change: What is Optimal and Appropriate?" In Climate Change and the Mediterranean: Socio-Economic Perspectives of Impacts, Vulnerability and Adaptation, eds. Carlo Giupponi and Mordechai Schechter. Cheltenham: Edward Elgar.

Larson, Milan D., and Karen Fowler. 2009. "Anticipation is in the Eye of the Beholder: TopLevel Managers see Things Differently when it Comes to Crises Preparedness." Journal of Business and Management 15 (2): 129-141.

Lorenzoni, Irene, Anthony Leiserowitz, Miguel de Franca Doria, Wouter Poortinga, and Nick F. Pidgeon. 2006. "Cross-National Comparisons of Image Associations with "Global Warming" and "Climate Change" Among Laypeople in the United States of America and Great Britain.” Journal of Risk Research 9 (3): 265-281.

National Oceanic and Atmospheric Administration. 2015. "State of the Climate." https://www.ncdc.noaa.gov/sotc/ 
New York State Division of Homeland Security and Emergency Management. 2014. "Section 3.0 - Hazard Identification and Risk Assessment. 2014 New York State Hazard Mitigation Plan." http:/www.dhses.ny.gov/oem/mitigation/documents/2014shmp/Section-3-0-3-2-HazardProfile-Risk-Assessment.pdf

O'Brien, Geoff, Phil O'Keefe, Joanne Rose, and Ben Wisner. 2006. "Climate Change and Disaster Management." Disasters 30 (1): 64-80.

O'Connor, Robert E., Richard J. Bord, and Ann Fisher. 1999. "Risk Perceptions, General Environmental Beliefs, and Willingness to Address Climate Change." Risk Analysis 19 (3): 461-471.

Ohio Emergency Management Agency. 2014. State of Ohio Hazard Identification and Risk Analysis. http://ohiosharpp.ema.state.oh.us/OhioSHARPP/Planning.aspx\#shmp

Olson, Kristen, and Bryan Parkhurst. 2013. "Collecting Paradata for Measurement Error Evaluations." In Improving Surveys with Paradata: Analytic Uses of Process Information, ed. Frauke Kreuter. New Jersey: Wiley \& Sons, 33-64.

Poussin, Jennifer K., WJ Wouter Botzen, and Jeroen C. J. H. Aerts. 2014. "Factors of Influence on Flood Damage Mitigation Behaviour by Households.” Environmental Science \& Policy 40 (1): 69-77.

Sadiq, A. A. 2011. "Adoption of Hazard Adjustments by Large and Small Organizations: Who is Doing the Talking and Who is Doing the Walking?" Risk, Hazards \& Crisis in Public Policy 2 (3): 1-17.

Sadiq, Abdul-Akeem, and John D. Graham. 2015. "Exploring the Predictors of Organizational Preparedness for Natural Disasters." Risk Analysis. DOI 10.1111/risa.12478

Sadiq, Abdul-Akeem, and Douglas Noonan. 2015. "Flood Disaster Management Policy: An Analysis of the United States Community Ratings System.” Journal of Natural Resources Policy Research 7 (1): 5-22.

Sadiq, Abdul-Akeem, and Christopher Weible. 2010. "Obstacles and Disaster Risk Reduction: Survey of Memphis Organizations." Natural Hazards Review 11 (3): 110-117.

Schulte, Paul A., and HeeKyoung Chun. 2009. "Climate Change and Occupational Safety and Health: Establishing a Preliminary Framework." Journal of Occupational and Environmental Hygiene 6 (9): 542-554.

Smit, Barry, and Johanna Wandel. 2006. "Adaptation, Adaptive Capacity and Vulnerability." Global Environmental Change 16 (3): 282-292.

Sterman, John D., and Linda Booth Sweeney. 2007. "Understanding Public Complacency About Climate Change: Adults' Mental Models of Climate Change Violate Conservation of Matter." Climatic Change 80 (3): 213-238.

Texas Division of Emergency Management (TDEM). 2013. "State of Texas Mitigation Plan." http://dps.texas.gov/dem/Mitigation/txHazMitPlan.pdf

Tierney, Kathleen. 2013. "Foreword.” In Disaster Resiliency: Interdisciplinary Perspectives, eds. Naim Kapucu, Christopher V. Hawkins, and Fernando I. Rivera. New York: Routledge, xiii-xvi.

United Nations Framework Convention on Climate Change (UNFCCC). 2011. "Fact Sheet: Climate Change Science - the Status of Climate Change Science Today." https://unfccc.int/files/press/backgrounders/application/pdf/press factsh science.pdf 
United Nations Office for Disaster Risk Reduction (UNISDR). 2013. "From Shared Risk to Shared Value -The Business Case for Disaster Risk Reduction." Global Assessment Report on Disaster Risk Reduction. Geneva, Switzerland: United Nations Office for Disaster Risk Reduction.

Van Aalst, Maarten K., Terry Cannon, and Ian Burton. 2008. "Community Level Adaptation to Climate Change: The Potential Role of Participatory Community Risk Assessment." Global Environmental Change 18 (1): 165-179.

Webb, Gary R., Kathleen J. Tierney, and James M. Dahlhamer. 2000. "Businesses and Disasters: Empirical Patterns and Unanswered Questions." Natural Hazards Review 1 (2): 83-90.

Westerling, Anthony L., Hugo G. Hidalgo, Daniel R. Cayan, and Thomas W. Swetnam. 2006. "Warming and Earlier Spring Increase Western US Forest Wildfire Activity." Science 313 (5789): 940-943.

Winn, Monika, Manfred Kirchgeorg, Andrew Griffiths, Martina K. Linnenluecke, and Elmar Günther. 2011. "Impacts from Climate Change on Organizations: A Conceptual Foundation." Business Strategy and the Environment 20 (3): 157-173.

World Meteorological Organization (WMO). 2014. "WMO statement on the status of the global climate in 2013." https://www.wmo.int/.../1152_en.pdf

Yeager, David S., Jon A. Krosnick, LinChiat Chang, Harold S. Javitz, Matthew S. Levendusky, Alberto Simpser, and Rui Wang. 2010. "Comparing the Accuracy of RDD Telephone Surveys and Internet Surveys Conducted with Probability and Non-Probability Samples." Public Opinion Quarterly, 75(4): 709-747.

$\mathrm{Yu}$, Hao, Bing Wang, Yue-Jun Zhang, Shouyang Wang, and Yi-Ming Wei. 2013. "Public Perception of Climate Change in China: Results from the Questionnaire Survey." Natural Hazards 69 (1): 459-472. 